\title{
(2) OPEN ACCESS \\ Agile Innovation to transform healthcare: innovating in complex adaptive systems is an everyday process, not a light bulb event
}

\author{
Richard J Holden (D) , ${ }^{1}$ Malaz A Boustani, ${ }^{1}$ Jose Azar ${ }^{2}$
}

\begin{abstract}
'Department of Medicine, Indiana University School of Medicine, Indianapolis, Indiana, USA

${ }^{2}$ Department of Medicine, Indiana University Health, Indianapolis, Indiana, USA
\end{abstract}

\section{Correspondence to} Dr Richard J Holden, Department of Medicine, Indiana University School of Medicine, Indianapolis, IN 46202, USA; rjholden@ iupui.edu

Received 19 October 2020 Revised 11 January 2021 Accepted 11 January 2021 Published Online First 28 January 2021

\section{Check for updates}

\section{(C) Author(s) (or their} employer(s)) 2021. Re-use permitted under CC BY-NC. No commercial re-use. See rights and permissions. Published by BMJ.

To cite: Holden RJ, Boustani MA, Azar J. BMJ Innov 2021;7:499-505.

\begin{abstract}
Innovation is essential to transform healthcare delivery systems, but in complex adaptive systems innovation is more than 'light bulb events' of inspired creativity. To achieve true innovation, organisations must adopt a disciplined, customer-centred process. We developed the process of Agile Innovation as an approach any complex adaptive organisation can adopt to achieve rapid, systematic, customercentred development and testing of innovative interventions. Agile Innovation incorporates insights from design thinking, Agile project management, and complexity and behavioural sciences. It was refined through experiments in diverse healthcare organisations. The eight steps of Agile Innovation are: (1) confirm demand; (2) study the problem; (3) scan for solutions; (4) plan for evaluation and termination; (5) ideate and select; (6) run innovation development sprints; (7) validate solutions; and (8) package for launch. In addition to describing each of these steps, we discuss examples of and challenges to using Agile Innovation. We contend that once Agile Innovation is mastered, healthcare delivery organisations can habituate it as the go-to approach to projects, thus incorporating innovation into how things are done, rather than treating innovation as a light bulb event.
\end{abstract}

\section{INTRODUCTION}

The scientific and technological evolution of US healthcare delivery has drastically improved longevity and quality of life. ${ }^{1}$ Evolution is accompanied by new challenges to deliver safe, high-quality, low-cost and positively experienced healthcare services to patients who are older, chronically ill and at higher risk of disability. ${ }^{2}$ Such challenges demand transformation of healthcare service delivery,

\section{Summary box}

What is already known?

- Innovation is needed to transform healthcare delivery and its outcomes.

- Innovation is too often envisioned in healthcare as occasional bouts of inspired creativity by so-called disruptive innovators, whereas innovation in other industries is understood to be a participatory customer-centred process.

What are the new findings?

- Agile Innovation is a customer-centred innovation process for complex adaptive systems that can be adopted in healthcare delivery organisations as an everyday process.

- Agile Innovation's eight steps uniquely combine best practices from design thinking, Agile project management and complexity and behavioural sciences.

- Habituating Agile Innovation in everyday practice requires discipline, resources and a psychologically safe culture.

beyond biomedical discovery. ${ }^{3}$ Although manufacturing-based change methodologies such as total quality management, lean and six sigma may eliminate waste and variability, they will not transform complex adaptive healthcare systems. ${ }^{4}$ Instead, healthcare delivery organisations are in dire need to innovate their delivery operations, following the lead of other industries, which rely on innovation to survive and thrive. ${ }^{5}$

The problem with innovation is it is often confused with invention and reduced to 'light bulb events' of inspired creativity pushed top-down by so-called disruptive innovators. Critics have argued the healthcare industry overvalues 


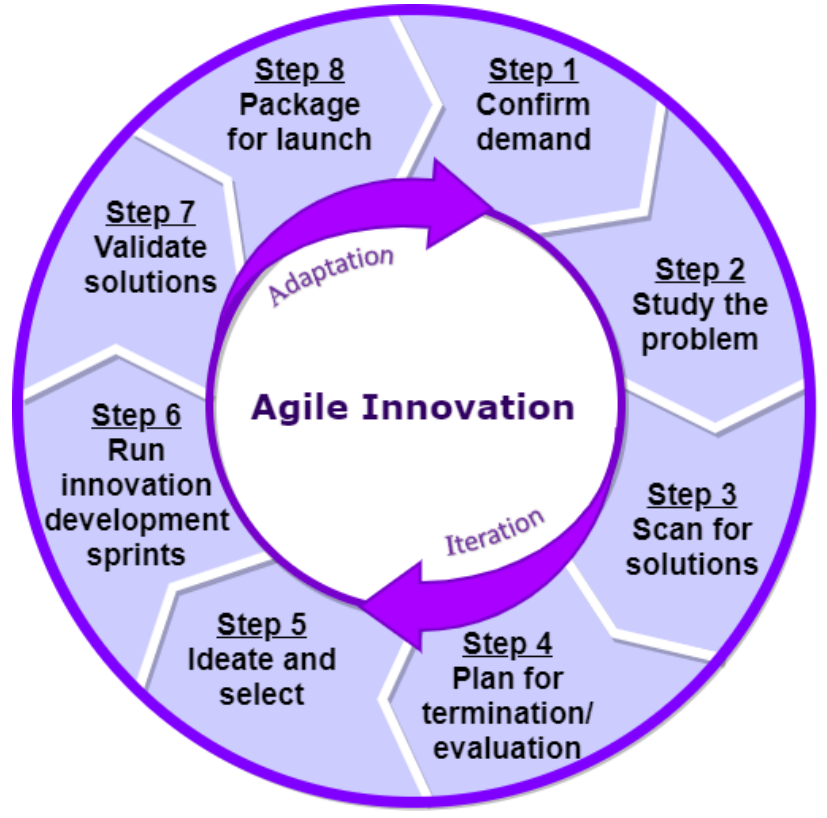

Figure 1 The eight-step Agile Innovation process.

creative or revolutionary solutions and 'neglects one of the essential elements of successful innovation, in both the technology sector and the broader economy: a disciplined approach to meeting consumers' needs' ${ }^{6}$ Healthcare delivery organisations must shift their definition of innovation 'from the generation of ideas to rapid methods of running experiments to test them'? In other words, healthcare delivery needs a customercentred and participatory process for innovation that can be sustained: that is, replicated and repeated. Such a process must allow teams on the ground to use rapid experimentation, respond to well-characterised problems, evaluate solutions and manage the messiness of the complex adaptive healthcare delivery systems where innovative solutions will eventually be implemented. ${ }^{8}$

\section{METHOD}

We developed Agile Innovation as a transformation approach for complex adaptive healthcare systems. Agile Innovation extended our work with Agile Implementation, an Agile approach to implementing evidence-based healthcare practices. ${ }^{4} 910$ Our Agile approach was rooted in industry best practices and Nobel Prize-winning science.

The first foundation for Agile Innovation was design thinking, a creative problem-solving approach, popularised by Stanford University and the IDEO company. ${ }^{11}$ Several steps of Agile Innovation are influenced by design thinking, namely steps for deeply understanding the context and problem to be solved, ideating and prototyping solutions, and testing. Agile Innovation also adopts design thinking's iterative approach.

The second basic foundation was Agile principles for software development and project management, ${ }^{12}$ where teams work intensively over short-cycle sprints to produce working solutions, test them with clients and obtain feedback to guide the next sprint. ${ }^{13}$ Agile project management was originally positioned as an eventual successor to lean, given Agile's ability to quickly respond to customer needs. ${ }^{14}$ Thus, Agile Innovation is strongly focused on customer needs, collecting and nimbly responding to customer feedback in sprint cycles, and empowering teams to autonomously adjust to demands rather than placing top-down constraints on the solution.

Complexity and behavioural sciences provided the third foundation; these depict humans as agents in complex adaptive systems. ${ }^{15} 16$ Specifically, Agile Innovation drew on Holland's theory of complexity, ${ }^{17}$ which posits signals and boundaries as the drivers of behaviours in complex adaptive social organisations. Local, non-linear exchanges of information and resources between organisational agents and their surrounding environment produce emergent and adaptive behaviour. This theory influenced Agile Innovation's non-linearity and orientation towards leveraging, not reducing, complexity, by empowering local agents to be adaptive and responsive to their local environment. Second, Agile Innovation was influenced by behavioural economics theories of human behaviour under high levels of information uncertainty. ${ }^{18}$ These theories propose that in conditions of uncertainty or incomplete data, human action is largely driven by cognitive processes that are instinctive, emotional and automated rather than analytic and effortful. Thus, Agile Innovation assumes people are adaptive and able to use cognitive short cuts, but those short cuts do not lead to what one might call 'rational' decisions.

We used insights from these foundational practices and theories to construct a working version of the Agile Innovation process. We refined Agile Innovation through numerous experiments in diverse healthcare organisations. ${ }^{410}$ These included Eskenazi Health, a safety net healthcare delivery system in Indianapolis; Indiana University Health, a state-wide integrated healthcare delivery system; and the Great Lakes Practice Transformation Network, a cluster of 2100 practices in rural, suburban and urban settings in Illinois, Indiana, Kentucky, Michigan and Ohio.

\section{RESULTS}

Agile Innovation has eight steps (figure 1), four for planning and four for execution. Innovation is nonlinear but the eight steps are generally done in forward order with as-needed repeating of parts of the process. Agile Innovation's iterative and cyclical process flow resembles other iterative approaches such as Plan-DoStudy-Act, where empirical findings influence future actions and result in further iterations of design and evaluation. Assumed but not formally described is the vital step of forming a team, which includes establishing participants, operating resources, expectations 
and timelines. Agile Innovation team roles generally include team leadership, product ownership (communicating the vision and setting priorities for the team) and roles responsible for studying/representing the problem and identifying/developing the solution. The team engages stakeholders-including subject matter experts, leaders and end users (customers)throughout the process.

\section{Step 1: confirm demand}

To avoid investing in a solution no one needs, Agile Innovation promotes early on defining the problem whose solution stakeholders demand. Demand is a perception residing in the stakeholders' minds, so confirming demand may require repeated stakeholder interaction to rule out fleeting interests. Innovators might convince stakeholders by empirically assessing the problem (step 2) but should not proceed too far until stakeholders agree on which problem needs solving and commit to finding solutions. In modern healthcare, the question of 'whose demand?' is pertinent; Agile Innovation promotes considering the demands of those in leadership positions because they control access to resources and of patients and other consumers, as their outcomes are paramount and their perspectives unique. ${ }^{19}$

\section{Step 2: study the problem}

Innovators can choose from and combine myriad methods for studying systems, processes and outcomes associated with the problem. Methods range from collecting broad ethnographic data while embedded in the local context to pulling longitudinal quantitative data on specific outcomes. Understanding how the sociotechnical system is currently designed helps develop innovations that will fit existing people, tools, tasks and environments. ${ }^{20}$ Empirical process mapping-workflow analysis, value stream mapping, user stories, journey maps-is especially useful because knowing how things are currently done reveals opportunities for future (re)design. ${ }^{21-23}$ It is easy to sink time in this open-ended early stage, so we advise innovators to: (1) rely on pre-existing research and data when possible; (2) use methods designed for speed and efficiency, for example, rapid ethnography, personas or surveys; (3) create clear data collection and analysis plans to avoid scope creep; (4) interleave analysis during data collection; and (5) designate one or more Problem Masters, who deeply know the problem and related data, to be consulted throughout. Recent work on Agile health information technology development describes using rapid ethnography, surveys and other methods to study problems in clinical ${ }^{2425}$ and community settings. ${ }^{2627}$ Moreover, innovators will never know the problem completely and must be comfortable with an understanding that is 'good enough' to create solutions whose testing will reveal whether the innovators adequately understood the problem or need to repeat this step. Patients and other consumers of healthcare are a critical party to step 2 , as their experiences, journeys, needs and preferences contribute uniquely and consequentially to defining the problem.

\section{Step 3: scan for solutions}

Innovators typically combine or modify elements of existing solutions in novel ways and apply them to novel problems, rather than inventing something completely new. ${ }^{28}$ In this step, innovators scan for existing solutions in typical and atypical repositories. Typical sources are peer institutions, published literature, online forums/sites and colleagues. Scanning atypical sources may be more innovative and inspiring; these include dissimilar disciplines or markets, consumer or advocacy groups advocating changes to the status quo and history books or museum exhibits. One can also crowdsource existing solutions from outsiders or insource from overlooked current practices and adaptations within the organisation. Such clever but localised internal solutions may have been uncovered in step 2.

\section{Step 4: plan for evaluation and termination}

Before creating the solution, one should plan how it will be evaluated and under what conditions its development should be terminated. ${ }^{29}$ This is done to ensure progress towards specific goals, rather than innovating for the sake of innovating. ${ }^{9}$ Having a termination plan makes it easier to overcome forward momentum; it reframes the decision to stop as a gain-an opportunity to invest in better alternatives-not a loss (of prior investments). Moving on from a solution that meets termination criteria is an occasion to celebrate. The termination plan should therefore include the release of additional resources to investigate what went wrong or could be recycled and to pursue new alternatives. However, because early-stage or late-stage project termination can be an emotional and political decision, specific termination criteria and timelines should be documented in advance and outside stakeholders should be consulted to verify that a solution meets termination criteria before it is stopped. For any solution that is not terminated early on, formal evaluation criteria should also be developed at this step, to be used in the next steps. Evaluation details-including planned measures and analyses-will depend on the specific project, but can include efficacy or effectiveness (eg, health outcomes), cost (eg, expenses, savings), efficiency (eg, amount of rework), acceptance (eg, satisfaction), reach (eg, per cent affected) and explanatory factors (eg, facilitating conditions). ${ }^{30}$

\section{Step 5: ideate and select}

Ideation is a hallmark of design thinking because it is a creative, non-judgmental process that participants enjoy and can easily associate with innovation. ${ }^{13}$ Generating free-form ideas, building on others' early thoughts and 


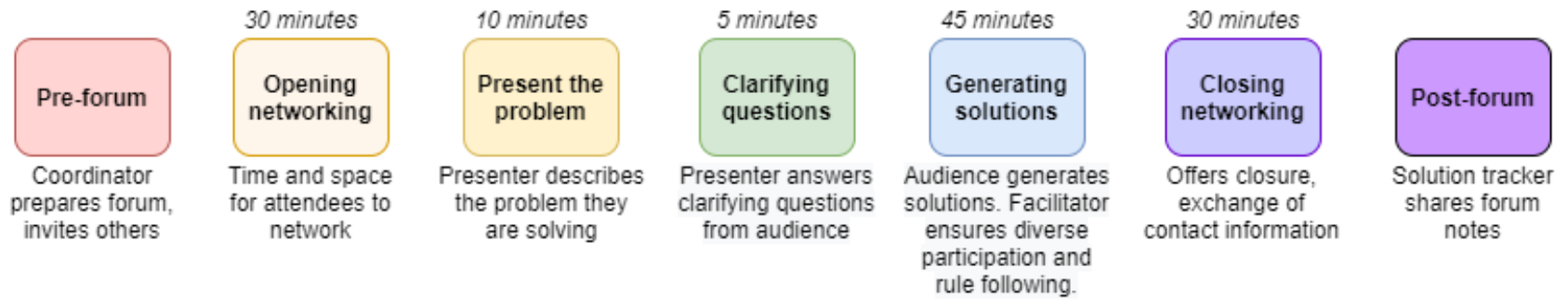

Figure 2 The Innovation Forum process.

stepping outside the confines of present reality to ask 'what if' questions can be stimulating and often lead to memorable ideas. As a result, ideation should be open to many participants, including prospective customers or end users. ${ }^{12} 31$ Broadening participation is mutually beneficial given evidence that diversity during ideation produces better, more creative and a greater volume of ideas. ${ }^{32}$ More mundane tasks accompany ideation, including recruiting participants for ideation sessions, facilitating these sessions and documenting ideas. Figure 2 depicts the Innovation Forum, a structured participatory design or codesign event that is fast, engaging and promotes the sharing of 'time and space' between the innovation team and local experts, including healthcare professionals, administrators and patient/family stakeholders. Other ideation session strategies abound, including breakout groups, competition and reward (although participating in ideation can be reward enough), story-telling or role-playing, sketching or collaging, questioning and tools for combining or contrasting ideas.

Ideation is exciting and free of judgement, but once ideas are generated, the hard work begins to use clear criteria (preferably those established in step 4) to narrow down the candidates to develop further. Example criteria for selecting solutions to further pursue include stakeholder support for the solution, production cost, likelihood that it will solve the problem, scalability and feasibility or viability. The selection or convergence process is difficult because it means discarding ideas. We therefore recommend framing selection as a formal, scientific process to prioritise investments in the most promising ideas.

\section{Step 6: run innovation development sprints}

Sprints are self-contained series of developing and testing a prototype of the solution. There may be many of these before moving to the next step. Rapid prototyping is often advisable to create something that is imperfect but 'good enough' to test. According to Agile philosophy, testing is a superior path towards progress and design decisions compared with introspection or polishing the design. This is true because testing allows actual customers or end users to interact with the solution, revealing how the solution performs in reality, not theory, and obtaining feedback grounded in front-line expertise. ${ }^{33}$ Reducing the delay between creating and testing also saves time for additional iterations, such that more sprints can be run before time and resources are exhausted. A typical strategy to manage multiple sprints is to progress from less costly lower fidelity to costlier but more interactive higher fidelity prototypes, reducing fidelity for major adjustments. This applies to prototypes of software (eg, from wireframe screens to field-ready software), physical products (eg, drawings to $3 \mathrm{D}$ printed artefacts), physical space (eg, cardboard to stable architecture) and processes (eg, verbal vignettes to dress rehearsals). One hospital-based Agile project described their sprint structure:

\begin{abstract}
The design team directly engaged clinician users to ensure design decisions and software requirements fit the true needs of the users and their clinical workflows. Using this approach, a new version of software was released once every 2-4 weeks during active development. The design team meets on a weekly basis to review feedback from users, on-going development tasks, and prioritize development activities including bug fixes and new features. ${ }^{23}$
\end{abstract}

\section{Step 7: validate solutions}

Sprints produce a high-fidelity minimum viable product (MVP) or minimum viable service (MVS). These do not contain all possible functionality but their included functions are properly working. The MVP or MVS can now be tested according to the evaluation plan established in step 4, preferably in realistic settings with actual end users. In Agile software development, validation usually centres on acceptance criteria, or evidence that the product has met customer needs. ${ }^{34}$ During validation, it is necessary to monitor for and address unintended consequences, unexpected benefits and emergent behaviours-an insight from complexity science. This can only be done by testing the innovation in practice and having adequate sensors in place to collect data on all results, expected or not. Ultimately, an innovation is not valid unless it meets customer needs, which increasingly include the needs of the patients and families who coproduce care. ${ }^{35}$

\section{Step 8: package for launch}

This step is necessary to ensure an innovative solution is implemented. The innovator creates the hand-off package, which includes a business plan, MVP/MVS 
and minimal critical specifications for use. Innovators must clearly state the essential, non-modifiable components of their solution, allowing the rest to be customised for local use. Innovators can leverage guidance for Agile software documentation ${ }^{36} 37$ and general advice on developing minimal standard operating procedures. ${ }^{9}$ This is a difficult step for innovators tempted to view every aspect of the solution as important. However, end users will modify the design regardless of innovators' wishes, so innovators should articulate vital components not to be changed.

\section{Examples of Agile Innovation in healthcare}

Agile approaches have been used in healthcare, ${ }^{38}$ including developing customer-centred software via user-centred and participatory design. ${ }^{23}$ One example is work led by technology researchers at Oregon Health \& Science University to improve electronic health records for primary and behavioural healthcare professionals. ${ }^{24}$ They used rapid ethnography to understand user needs and generate requirements. Requirements were then addressed, leveraging existing software tools and developing new ones. Iterative prototype testing with end users allowed the team to assess whether actual customers (clinicians) found the software usable and acceptable, resulting in software refinements and eventually validated products packaged for clinical implementation.

A second example is University of Texas Southwestern Health System's Agile development of clinical decision support tools. ${ }^{39}$ The team developed user stories and diagrams to depict the problem, then created prototypes to represent potential solutions. They used a rapid sprint cycle to obtain customer feedback on product iterations, deployed every 2 weeks. When the team could not gather feedback from actual clinicians, well-informed surrogates served as the 'voice of the customer' (a role we call 'Problem
Masters'). Their evaluations leveraged quantitative and qualitative results.

Lastly, Indiana University researchers and clinicians at Eskenazi Health collaboratively developed a software for clinicians and informal caregivers of persons with dementia. They performed all eight steps of Agile Innovation, summarised in table 1 . Clinicians participated in codesign sessions, providing input on software features before and after the software was clinically deployed, while informal caregivers provided input through usability testing and participating in a pilot clinical trial. ${ }^{40}$

\section{DISCUSSION}

We argued at the outset that a disciplined, customercentred process is preferable to and more sustainable than innovating from disruptive individuals' flashes of brilliance. Although lean, six sigma and other traditional quality improvement models also offer systematic processes, they generally 'fail to acknowledge and account for the complex nature and unique characteristics of individual healthcare systems' ${ }^{41}$ Those who view healthcare organisations as complex adaptive systems criticise lean's preference for standardisation over embracing needed variation. ${ }^{42}$ Traditional quality improvement systems fail to innovate when they primarily strive towards efficiency and reducing complexity rather than adapting to customer needs. ${ }^{43}$ Although exceptions have been reported of innovative lean manufacturing ${ }^{44}$ and healthcare delivery, ${ }^{45}{ }^{46}$ Agile Innovation is uniquely and purposefully designed for sustainable, customer-centred innovation in complex adaptive healthcare systems. It complements other customer-centred approaches, such as evolving movements to involve clinicians and non-professional (eg, patients, families) coproducers of care in healthcare decisions. ${ }^{35} 4748$ Like those movements, Agile

\begin{tabular}{l} 
Table 1 Use of Agile Innovation to develop the Brain CareNotes mobile app for dementia care \\
\hline Agile Innovation steps \\
\hline 1. Confirm demand. \\
2. Study the problem.
\end{tabular}


Innovation promotes the voice and active involvement of the customer. The customer is defined case by case, but in most modern paradigms includes patients and families. ${ }^{49}$

Like any process, Agile Innovation has its challenges. Agile Innovation requires investing adequate human resources, time and patience for iteration, apart from any material resources. Another practical challenge is balancing creative thinking with the scientific method, without letting either become a barrier to forward progress. A keen observer will also note that Agile Innovation is a customer-centred process and democratic, by empowering local teams to conduct experiments to test with end users, including patients; thus, it only survives in a psychologically safe culture that values customers, participation and experimentation. ${ }^{50}$ Lastly, the steps are relatively simple to understand, but difficult to master. Healthcare organisations might initially partner with designers or engineers to apply Agile Innovation and gain mastery and internal capacity.

Future work should: (A) document step-by-step uses of Agile Innovation, including challenges faced and strategies used to overcome them; (B) develop off-the-shelf tools, including software, to support training on and implementation of Agile Innovation; (C) compare outcomes of Agile Innovation to other approaches such as traditional quality improvement methods; (D) examine whether Agile Innovation can be sustained as an organisational practice over a long period and which factors promote sustainability; and (E) develop new theories and methods for introducing Agility, innovation, participatory design and customercentredness in healthcare.

\section{CONCLUSION}

Organisations that have mastered Agile Innovation can habituate it as their go-to approach to projects, becoming an Agile organisation where innovation is the process for how things are done, not serendipitous light bulb events.

Acknowledgements We thank the members of the Center for Health Innovation and Implementation Science and our partner health systems for helping develop, test and refine the Agile Innovation and Agile Implementation processes. We also thank two anonymous reviewers.

Contributors This paper was conceived and written by RJH, $\mathrm{MAB}$ and JA. All authors contributed to editing, revising and final approval.

Funding The authors have not declared a specific grant for this research from any funding agency in the public, commercial or not-for-profit sectors.

Competing interests $\mathrm{MAB}$ is the founder of and holds equity in Preferred Population Health Management, an information technology company.

Patient and public involvement Patients and/or the public were not involved in the design, or conduct, or reporting, or dissemination plans of this research.

Patient consent for publication Not required.
Provenance and peer review Not commissioned, externally peer reviewed.

Data availability statement No data are available.

Open access This is an open access article distributed in accordance with the Creative Commons Attribution Non Commercial (CC BYNC 4.0) license, which permits others to distribute, remix, adapt, build upon this work non-commercially, and license their derivative works on different terms, provided the original work is properly cited, appropriate credit is given, any changes made indicated, and the use is non-commercial. See: http://creativecommons.org/ licenses/by-nc/4.0/.

ORCID iD

Richard J Holden http://orcid.org/0000-0002-3603-6158

\section{REFERENCES}

1 Dzau VJ, Inouye SK, Rowe JW, et al. Enabling healthful aging for all - the national academy of medicine grand challenge in healthy longevity. N Engl J Med 2019;381:1699-701.

2 Institute of Medicine. Best care at lower cost: the path to continuously learning health care in America. Washington, DC: National Academies Press, 2013.

3 Institute of Medicine. Building a better delivery system: a new Engineering/Health care partnership. Washington, DC: National Academies Press, 2005.

4 Boustani M, Holden RJ, Azar J, et al. The Agile network: a model to foster innovation, implementation, and diffusion in healthcare settings. Saint Paul, MN: Beaver's Pond Press, 2020.

5 Liedtka J. Why design thinking works. . Harvard Business Review, 2018: 96. 72-9.

6 Schulman KA, Richman BD. Toward an effective innovation agenda. N Engl J Med 2019;380:900-1.

7 Asch DA, Rosin R. Innovation as discipline, not FAD. N Engl J Med 2015;373:592-4.

8 Dixon-Woods M, Amalberti R, Goodman S, et al. Problems and promises of innovation: why healthcare needs to rethink its love/hate relationship with the new. BMJ Qual Saf 2011;20:i47-51.

9 Boustani MA, van der Marck MA, Adams N, et al. Developing the Agile implementation Playbook for integrating evidencebased health care services into clinical practice. Academic Medicine 2019;94:556-61.

10 Boustani M, Azar J, Solid CA. Agile implementation: a model for implementing evidence-based healthcare solutions into realworld practice to achieve sustainable change. Morgan James Publishing, 2020.

11 Plattner H, Meinel C, Leifer L. Design thinking: understand improve - apply. Berlin: Springer, 2011.

12 Kitzmiller R, Hunt E, Sproat SB. Adopting best practices: "Agility" moves from software development to healthcare project management. Comput Inform Nurs 2006;24:75-82.

13 Highsmith J. Agile project management: creating innovative products. 2 edn. Pearson, 2010.

14 Dove R. Knowledge management, response ability, and the agile enterprise. Journal of Knowledge Management 1999;3:18-35.

15 Gomersall T. Complex adaptive systems: a new approach for understanding health practices. Health Psychol Rev 2018;12:405-18.

16 Kahneman D. Maps of bounded rationality: psychology for behavioral economics. Am Econ Rev 2003;93:1449-75.

17 Holland JH. Signals and boundaries: building blocks for complex adaptive systems. Cambridge, MA: MIT Press, 2012.

18 Kahneman D. Thinking, fast and slow. Macmillan, 2011. 
19 Institute of Medicine. Patients Charting the course: citizen engagement and the learning health system: workshop summary. Washington, DC: National Academies Press, 2011.

20 Holden RJ, Carayon P, Gurses AP, et al. SEIPS 2.0: a human factors framework for studying and improving the work of healthcare professionals and patients. Ergonomics 2013;56:1669-86.

21 Carayon P, Wooldridge A, Hoonakker P, et al. SEIPS 3.0: Human-centered design of the patient journey for patient safety. Appl Ergon 2020;84:103033.

22 Asmar L, Rabe M, Low CY, et al. Framework for the agile development of innovative Product-Service-Systems for existing physical rehabilitation systems. Procedia Manuf 2018;24:147-52.

23 Tang T, Lim ME, Mansfield E, et al. Clinician user involvement in the real world: designing an electronic tool to improve interprofessional communication and collaboration in a hospital setting. Int J Med Inform 2018;110:90-7.

24 Cohen DJ, Wyte-Lake T, Dorr DA, et al. Unmet information needs of clinical teams delivering care to complex patients and design strategies to address those needs. J Am Med Inform Assoc 2020;27:690-9.

25 Clark KD, Woodson TT, Holden RJ, et al. Translating research into Agile development (triad): development of electronic health record tools for primary care settings. Methods Inf Med 2019;58:001-8.

26 Campbell JI, Aturinda I, Mwesigwa E, et al. The technology acceptance model for resource-limited settings (TAM-RLS): a novel framework for mobile health interventions targeted to low-literacy end-users in resource-limited settings. AIDS Behav 2017;21:3129-40.

27 Holden RJ, Srinivas P, Campbell NL, et al. Understanding older adults' medication decision making and behavior: a study on over-the-counter (OTC) anticholinergic medications. Res Social Adm Pharm 2019;15:53-60.

28 Dyer JH, Gregersen HB, Christensen CM. The innovator's DNA. Harv Bus Rev 2009;87:60-7.

29 Øvretveit J, Gustafson D. Evaluation of quality improvement programmes. Qual Saf Health Care 2002;11:270-5.

30 Chaudoir SR, Dugan AG, Barr CHI. Measuring factors affecting implementation of health innovations: a systematic review of structural, organizational, provider, patient, and innovation level measures. Implement Sci 2013;8:22.

$31 \mathrm{Mu} \mathrm{Y,} \mathrm{Bossink} \mathrm{B,} \mathrm{Vinig} \mathrm{T.} \mathrm{Employee} \mathrm{involvement} \mathrm{in}$ ideation and healthcare service innovation quality. Serv Ind $J$ 2018;38:67-86.

32 Hewlett SA, Marshall M, Sherbin L. How diversity can drive innovation. 91. Harvard business review, 2013.
33 Schwaber K, Beedle M. Agile software development with Scrum. Upper Saddle River, NJ: Prentice Hall, 2002.

34 Pugh K. Lean-agile acceptance test-driven development: better software through collaboration. Boston, MA: Pearson Education, 2010.

35 Batalden M, Batalden P, Margolis P, et al. Coproduction of healthcare service. BMJ Qual Saf 2016;25:509-17.

36 Rubin E, Rubin H. Supporting agile software development through active documentation. Requir Eng 2011;16:117-32.

37 Hadar I, Sherman S, Hadar E. Less is more: architecture documentation for agile development. IEEE 2013:121-4.

38 Tolf S, Nyström ME, Tishelman C, et al. Agile, a guiding principle for health care improvement? Int J Health Care Qual Assur 2015;28:468-93.

39 Kannan V, Willett D. Agile clinical decision support development, 2016. Available: https://www.agilealliance. org/wp-content/uploads/2017/02/Agile-Clinical-DecisionSupportDevelopment.pdf

40 Braly T, Muriathiri D, Brown JC, Holden RJ, et al. Technology intervention to support caregiving for Alzheimer's disease (ICARE): study protocol for a randomized controlled pilot trial. Pilot Feasibility Stud 2021;7:23.

41 Boustani M, Alder CA, Solid CA. Agile implementation: a blueprint for implementing evidence-based healthcare solutions. J Am Geriatr Soc 2018;66:1372-6.

42 Young RA, Roberts RG, Holden RJ. The challenges of measuring, improving, and reporting quality in primary care. Ann Fam Med 2017;15:175-82.

43 Browning TR, Sanders NR. Can innovation be lean? Calif Manage Rev 2012;54:5-19.

44 Byrne G, Lubowe D, Blitz A. Using a lean six sigma approach to drive innovation. Strat Leader 2007;35:5-10.

45 Aa A, Dulaimi M, Ellahham S. Using lean management to leverage innovation in healthcare projects: case study of a public hospital in the UAE. BMJ Innov 2016;2:22-32.

46 Toussaint JS, Berry LL. The promise of lean in health care. Mayo Clin Proc 2013;88:74-82.

47 Bergerum C, Thor J, Josefsson K, et al. How might patient involvement in healthcare quality improvement efforts work-A realist literature review. Health Expect 2019;22:95264.

48 Greenhalgh T, Humphrey C, Woodard F. User involvement in health care. Hoboken, NJ: John Wiley \& Sons, 2010.

49 Holden RJ, Design BM. Usability Methods: Agile Innovation and Evaluation of Interventions for Patients and Families. In: Holden RJ, Valdez RS, eds. The patient factor: theories and methods for patient Ergonomics, 2021.

50 Holden RJ, Boustani M. The value of an 'Agile' mindset in times of crisis. Modern Healthcare, 2020. 